\title{
Parents and the Preschool PATHS (Promoting Alternative Thinking Strategies) Curriculum
}

\section{Background}

The Preschool PATHS implementation project was developed and implemented by Glasgow Psychological Service and related preschool specialists. It has run for over five years, attracting government funding (Fairer Scotland and Lottery Fund) for the purchase of Preschool PATHS packs. It reflects current high levels of concern about the welfare and wellbeing of very young children and an evolving long term commitment to changing priorities and values in Scotland to focus more on intervention effectiveness, especially in the preschool years.

Currently sixteen establishments in Glasgow South have taken part in the Preschool PATHS Project and other establishments are becoming involved, overseen by Glasgow East and West Psychological Service. Demographics are mixed in Glasgow South Area with considerable poverty, disadvantage and unemployment affecting a large percentage of children and families. To date evaluations of the PATHS project focus on the Glasgow South area and include a 'Pulsion` Parent Survey donated by Glasgow University and the creation of a data base looking at trends in practitioner reported views on effects of Preschool PATHS on more than 270 preschool children.

\section{Contexts for concern}

Throughout their school years and beyond the developmental trajectory for children with early behaviour problems and associated social and emotional skill deficits is discouraging. Their difficulties impact long term on wellbeing, mental health and achievement. At the point of transition to school affected pre-schoolers are at risk of difficulties including poor relationships with peers and poor attainment (Domitrovich, 2007; Bierman and Welsh, 1997). In the later school context the importance of early intervention is emphasised by accumulating research demonstrating the rapid 
creation of a vicious cycle of challenging behaviour, teacher and peer rejection and school and social failure (Rathvon, 2008).

Many challenging children acquire behaviour patterns in homes where appropriate ways of managing negative feelings have not been modelled or taught, inadvertently reinforcing coercive patterns of interaction (Patterson et al, 1992). Challenging behaviour in young children is described as `any repeated pattern of behaviour that interferes or is at risk of interfering with optimal learning or engagement in pro social interactions with peers and adults ' (Smith and Fox, 2003, p.6). It includes physical and verbal aggression, prolonged tantrums, disruptive motor or verbal responding, non-compliance, destruction of property, self-injury and withdrawal. Recently, more researchers and educators note an increasing number of children with challenging behaviours arriving in preschool provision (Fox et al, 2003).

Children's` early behavioural problems are closely related to parenting skills and flag up risk of subsequent referral for conduct disorder, currently the main reason for referral to child mental health services in the UK and US. The treatment of conduct disorder in the short and longer term is costly across education, health, and social care and justice systems (NICE, 2006; Domitrovich, 2007)

Governments currently invest substantially to improve quality of life and outlook for children, supporting parents and children via a wide range of legislation, policies, projects, strategies and approaches (Durlack et al 2008). In the UK, the government consultation paper 'Every Child Matters: Change for Children', (Department for Education and Skills, 2004) highlighted the need to provide high quality, professionally delivered interventions for parents and carers. In Scotland, `Getting it Right for Every Child` (Scottish Government, 2006) and more recently the 'National Parenting Strategy` (Scottish Government, 2012)and the Early Years Collaborative ( Scottish Government, 2013) reflect significant, on-going investment in improving parenting skills with a view to improving outcomes for children. 
Challenges to the effectiveness of interventions: theoretical models, complex ecologies, multistranded interventions, implementation.

The complex web of children's social, emotional and behavioural difficulties and associated multifaceted, contextual factors such as parenting skills and teaching strategies, school ethos and community issues suggest that interventions require to be multi- stranded, complex and integrated to address problems effectively (Kelly, Ryan and Altman, 2000). Prevention Science and epidemiological research have contributed to our understanding of the myriad of factors that increase and buffer risk for developing problem behaviours and early emotional difficulties (Flay, 2005; Domitrovich, 2010). A good example of a comprehensive approach to problem complexity is provided by the Prosper Delivery System (Spoth and Greenberg, 2011). At present, this type of comprehensive model simultaneously targeting child, home, school and community is relatively rare and dependent on shared understandings of and investment in processes and evidence underlying real world ecologies and linked implementation strategies.

Developing, evidencing and implementing effective, multi -stranded preschool social and emotion based interventions requires to become top priority for researchers, policy advisers, educators and others. At this point, effective early social and emotional interventions with robust evidence are uncommon and linked interventions where parents and children learn together are even more unusual. A range of barriers to effective intervention reflect the complexity of the problem to be tackled.

Table 1

\begin{tabular}{|l|l|}
\hline $\begin{array}{l}\text { Key areas for } \\
\text { development }\end{array}$ & \multicolumn{1}{c|}{ Barriers to effective intervention } \\
\hline Evidential status & $\begin{array}{l}\text { High quality evidence has been slow to emerge in relation to what works in } \\
\text { tackling supported development of cooperation and self -regulation in } \\
\text { preschool and older children }\end{array}$ \\
\hline $\begin{array}{l}\text { Implementation } \\
\text { Science }\end{array}$ & $\begin{array}{l}\text { Where effective programmes exist, their effectiveness will vary considerably } \\
\text { across contexts depending on how much is invested in the implementation } \\
\text { processes. Many programmes shown to be effective in clinical trials fail to }\end{array}$ \\
\hline
\end{tabular}




\section{Potential of universal preventative programmes}

Prevention research suggests that universal skill development interventions are important prevention components in the development of comprehensive strategies to reduce children`s mental health problems and improve competencies. Early integrated preventative programmes for parents and children may have greater likelihood of success and prove most cost effective (Domitrovich et al, 2010). As elsewhere, high quality evidence in this category has been slow to establish. In the preschool context there is now some evidence based interventions for parents, children and teachers (Allen, 2011; Farrington and Welsh, 2007) but few have been evaluated using RCTs with adequate sample size, adequate and valid measures of outcome and with demonstrated effective replication in service settings.

\section{The Preschool PATHS Curriculum}

The Preschool PATHS (Promoting Alternative Thinking Strategies) Curriculum is one of a very few preschool universal, classroom based, social, emotional and behavioural interventions that has been evaluated in randomised control trials with populations of children under five (Izard et al 2004). RCTs of the Preschool PATHS programme were incorporated into 'Head Start' which is the largest 
provider of early childhood education for disadvantaged children in the US and required to provide for all children who are eligible for the programme, including children with established emotional and behavioural disorders. The mental health component of Head Start had been identified as needing to be strengthened (Fantuzzo et al, 2003).

The Preschool PATHS is an adaptation of the PATHS Curriculum for school aged children. It aims to promote child mental health and social and emotional competence via a structured curriculum with a clear theoretical basis and linked measureable developmental objectives. Children receiving Preschool PATHS teaching show better post intervention emotion knowledge, self-regulation and related skills compared to controls. Teachers and parents describe children as better adjusted, exhibiting higher levels of social interaction, emotion regulation and social skills (Domitrovich, 2007).

Although Preschool PATHS does not target parental behaviours or environmental conditions, the authors suggest that a more intensive` integrated` intervention model could be developed to include parents. The integration of different programmes or distinctive strands of the same programme with delivery to more recipients intensifies exposure and tackles complexities by widening the reach and focus of the intervention (Guerra and Bradshaw, 2008).

The Incredible Years suite of programmes is one of very few examples offering a range of integrated programmes for parents and teachers of children from birth to twelve years. Most aspects of the Incredible Years programmes have high quality evidence, tested in RCT trials across several different countries with most robust evidence reported for the 3-8 year age group (Bywater et al, 2010). Training originally devised for parents has been adapted for teachers, training them to apply effective strategies for misbehaviour, build positive relationships with difficult children, strengthen children's social skills and also collaborate with parents. The Incredible Years is well evidenced and substantiated by current views on the required scope and integration of universal and related intervention to achieve sustainable effects. However effective implementation of any programme is essential to its success. 


\section{Developing implementation focus}

In implementation as well as intervention contexts extensive evidence highlights the insufficiency of single strand methodology to support effectiveness. Currently, only $5 \%$ to $15 \%$ of programmes and interventions reach intended outcomes (Van Dyke, 2014). There are no options or shortcuts to designing careful and flexible implementation processes for any programme or intervention. Failing to do so will almost certainly guarantee the failure of the programme (Kelly and Perkins, 2012; Mihalic et al 2002). Implementation Science provides frameworks and evidence for effective implementation of programmes and indirectly provides evidence on the development and improvement of services. In implementation, regulations and mandates, funding or incentives, diffusion of information or training alone are not likely to promote effectiveness (Blasé et al 2012). Several linked areas of function need to be tackled to ensure effective programme implementation.

The implementation protocols for the Preschool PATHS in Glasgow City were based on evidence supporting `essential steps` in implementation processes (Meyers, Durlack and Wandersman, 2012) and on the NIRN (National Implementation Research Network) Core Implementation Components Blasé et al 2014;Van Dyke, 2014). The broad aims of implementation are to develop practitioner knowledge, skills and collaborative networks to support their delivery of the programme via development of readiness, training, monitoring, evaluation, networking and constructive feedback.

Core Components identify processes essential to implementation effectiveness: Recruitment and Selection; Preservice Training; Consultation and Coaching; Staff Performance Evaluation; Decision Support Data Systems; Facilitative Administrative Supports and Systems Interventions. Each of these components has a distinctive and indispensable role in relation to programme implementation, delivery and outcomes. Recruitment and Selection identify practitioner characteristics and values which are not established easily by training alone, for example; knowledge of a field, conviction about the usefulness of a programme, openness and empathy and willingness to learn. In this implementation, initial selection of practitioners was supported by the use of the Evidence Based 
Practice Attitude Scale (EBPAS) (Aarons, 2004). The 'readiness`concept addresses practitioner attitudes to: the intuitive appeal of the intervention; organizational requirements linked to innovation; openness to innovation and divergence of evidence based innovation from usual practice. There is accumulating evidence that these key attitudes are related to a number of individual and organizational characteristics which are in turn related to the likelihood that evidence based practice or interventions will be adopted as intended. Preservice and In-service Training are essential in targeting practitioners' need for in depth information on theory and practice implications of any programme or intervention and should provide an understanding of the underpinning rationale, purpose and evidence. However training alone is generally insufficient to support skill development and follow up Coaching and Consultation is essential to develop and sustain effective practitioner skills. Effective implementation requires the on-going assessment of practice to develop and improve service to clients. Staff Performance Evaluation protects the quality and fidelity of programme delivery, avoiding variability and 'drift' which is often (though not always) unhelpful in maintaining programme quality (Bumbarger and Perkins 2008). Decision Support Data Systems are required to continuously assess key aspects of the overall planning, delivery and support of the intervention and enable informed decision making. Facilitative Administration addresses the quality and impact of leadership reflected in policies, procedures, structures, culture and climate aiming, at least in the longer view, to align these appropriately with the needs of high quality implementation. Systems Interventions form a cluster of strategies ensuring the financial, organizational, and human resources required to support and sustain the work of practitioners.

Table 1 summarises how the challenges presented by the Core Components were met in practice. The implementation process is `on-going and can be applied as a continuous quality improvement cycle. 
Table 2 Framework for Implementation of Preschool PATHS

(Promoting Alternative Thinking Strategies) Curriculum

In Glasgow City

Pre Service Training, Recruitment and Selection; Readiness

Provide a New User Training Event

Assess Practitioner Readiness and commitment

Provide information on web pages and by presentation on Preschool PATHS for practitioner and management
- Key members are also members of the steering group and carry information from the field to the steering group

- Accesses and holds an overview of practitioner attitudes and needs via visits, meetings and questionnaires

- Organises active liaison with practitioners, notes any adjustments to the implementation and evaluation design to suit the local ecology

- Reports to the steering group, contributing to evaluation design, data analysis and circulation of information and reports

- Runs a regular PATHS Network event to allow practitioners to share experience and review and request training

- Provides training on topics linked to PATHS

- Contributes to the refinement and improvement of processes supporting delivery and sustainability

- Working Group informs potential users of theory and evidence supporting PATHS

- Enables practitioners to understand the objectives and processes of Implementation Science and the Core Drivers and how these are linked to the quality of their delivery and effectiveness

- Explains the implications of not following the implementation process i.e. fidelity issues

- Explains the range of factors enhancing effective implementation

- Assesses 'readiness` to begin interventions via a questionnaire at the New Users Training Event

- Informs the Steering Group of establishments and practitioners selected based on readiness responses 


\begin{tabular}{|c|c|}
\hline & $\begin{array}{l}\text { - Advises on development to reach readiness for those not } \\
\text { selected }\end{array}$ \\
\hline $\begin{array}{l}\text { Coaching and Consultation } \\
\text { Establish sources and availability } \\
\text { of expertise within Glasgow City } \\
\text { Authority } \\
\text { Establish an evidence based } \\
\text { approach to training practitioners }\end{array}$ & $\begin{array}{l}\text { - A pre -existing Preschool Peripatetic Team with experience in } \\
\text { teaching and supporting preschool establishments provided } \\
\text { coaching and modelling to train practitioners in PATHS } \\
\text { delivery } \\
\text { - Training of trainers was by observation of experienced } \\
\text { delivery in other authorities and review, discussion and } \\
\text { evaluation of evidence at the Steering and Network Groups }\end{array}$ \\
\hline $\begin{array}{l}\text { Decision support data systems } \\
\text { Gather data in key areas to } \\
\text { measure effective implementation } \\
\text { and impact of PATHS } \\
\text { Consider and implement changes }\end{array}$ & $\begin{array}{l}\text { - Steering Group and Working Group design and carry out a } \\
\text { range of projects to monitor and evaluate both } \\
\text { implementation processes and effects of PATHS } \\
\text { - Provide information in presentations and publications } \\
\text { - Monitor the quality of training via observation and checklist } \\
\text { - Monitor the quality of delivery in preschool contexts via } \\
\text { - } \text { observation and checklist } \\
\text { - Responds to adaptations and innovations }\end{array}$ \\
\hline $\begin{array}{l}\text { Facilitative administrative } \\
\text { supports } \\
\text { Acquire funding and endorsement } \\
\text { Provide leadership which is } \\
\text { collaborative, listening and } \\
\text { responding effectively to } \\
\text { practitioner issues and concerns } \\
\text { Solve problems in implementation } \\
\text { Scale up appropriately } \\
\text { Be aware of threats to fidelity and } \\
\text { skill development }\end{array}$ & $\begin{array}{l}\text { - Steering Group and Working Group address changes in } \\
\text { resourcing and sustainability of input } \\
\text { - Resists the temptation to scale up without high quality } \\
\text { implementation } \\
\text { - Informs Education Management of Implementation Science, } \\
\text { programme selection and quality improvement cycles in } \\
\text { implementation } \\
\text { - Links with researchers and external bodies to improve } \\
\text { implementation and practice }\end{array}$ \\
\hline
\end{tabular}

\section{Parent engagement}

Information was gathered on practitioner views of the implementation process. Information relating to parents derived from three sources: qualitative analysis of parents` responses to telephone interview on their knowledge and perceived impact of Preschool PATHS; practitioners' reports of unsolicited comments by parents on PATHS and preschool practitioners' reports of their parent engagement strategies which they delivered spontaneously. 
In the Preschool PATHS programme parent involvement is tackled formally only through homework activities but no formal, integrated parent training is included currently. In this project practitioners identified the need to engage parents providing a range of information and activities. These were inspired by parent requests for more information and arose largely from parent involvement in homework activities. Examples of innovations in parent engagement are listed below.

- Provision of information leaflets at the beginning of the programme

- Information sessions for parents and carers

- Informal dialogue about PATHS objectives

- PATHS notice board displaying lessons

- Parents` PATHS meetings and workshops explaining PATHS, introducing puppets and talking about lessons and the important role of parents at home

- Coverage in school Standards and Quality Reports and Improvement Plans

The same respondents were asked about their impressions of parents 'views of the Preschool PATHS Curriculum based on unsolicited parent comments

- Parents say children are talking about the lessons

- Children using more language to talk about how they are feeling

- Children using the 'Stop, Think and Speak' principles at home

- Whole families reminding each other to 'do turtle'

- Parents happy with their child's understanding of emotion

- Children have taught their parents to calm down and use the 'Twiggles going into his shell' technique

- Parents more willing to help their children express their feelings and name feelings

- Parents given compliments by their children

- Parents enjoying information on PATHS and children's comments

- Parents very enthusiastic about extension material sent home

- Parents see improvement in children's behaviour overall

A small project exploring the views of parents via telephone interview was part of the PATHS implementation evaluation and strongly endorsed the idea that parents want and need to know more about PATHS and some parents want to be actively involved. While the majority of parent respondents endorsed PATHS they felt that preschool establishments needed to do more to communicate effectively and include and prepare parents for active involvement. Better communication about PATHS before it begins was seen to be very important. Most parents felt they had learned more about PATHS from their children rather than from establishments (Neill, 2013).

\section{What are the implications for Preschool PATHS parent involvement?}

The spontaneous involvement of parents by preschool establishments is an unusual programme innovation. It does not affect the implementation of the programme directly but evidence suggests it may well affect outcomes. There is a strong evidence for the effectiveness of well -structured and well implemented parent training interventions and evidence for integrated child and teacher programmes for the prevention of problem behaviour. The impact of less formal parent involvement 
is difficult to establish. A recent review of parental involvement and attainment with long term results and based on high quality evaluations mixed parental engagement with an array of other intervention elements making it impossible to measure the nature and impact of parental engagement alone (Gorard and Huat See, 2013). The authors suggested that supporting and inviting parental involvement may create a backdrop for parents and children to learn effectively together and may train parents by allowing then to access teaching materials and processes.

This project highlights practitioner views of the role of parents in Preschool PATHS at a number of levels. Information they present on parent responses provides guidance on how to develop and implement key aspects of parent engagement and even on how to structure and deliver parent training materials. Table $\mathbf{2}$ highlights how innovations might be designed achieved within the existing implementation framework.

Table 2 Parents and Implementation of the Preschool PATHS

\begin{tabular}{|c|c|}
\hline Implementation Step & Strategies in use across schools to engage parents \\
\hline $\begin{array}{l}\text { Facilitative } \\
\text { Administrative Supports }\end{array}$ & $\begin{array}{l}\text { Provide information about the introduction of PATHS: } \\
\text { - Information leaflets at the beginning of the programme: The Big PATHS } \\
\text { Book; PATHS information wall; PATHS notice board displaying lessons; } \\
\text { Specific PATHS Letters } \\
\text { - Information sessions for parents and carers } \\
\text { - Inform parents via newsletter }\end{array}$ \\
\hline $\begin{array}{l}\text { Pre service training for } \\
\text { parents }\end{array}$ & $\begin{array}{l}\text { Introductory sessions for parents on the theory and objectives of the PATHS } \\
\text { - Introduction to the materials and video material showing how lessons are } \\
\text { - } \quad \text { Paught } \\
\text { about the lessons and the important role of parents picking up themes at } \\
\text { - home } \\
\text { - Introduction to PATHS homework } \\
\text { - } \quad \text { Parent suggestions for involvement }\end{array}$ \\
\hline $\begin{array}{l}\text { Decision support data } \\
\text { systems }\end{array}$ & $\begin{array}{l}\text { Gather data on parent involvement and consider how this might evidence impact } \\
\text { and support local and national policy developments }\end{array}$ \\
\hline
\end{tabular}

\section{Conclusion and future developments}

Applying Implementation Science

The application of effective implementation frameworks is essential to the success and evaluation of programme delivery and to any intervention where planned change is required. Implementation issues need context specific processes and long term commitment and flexibility in dealing with 
emerging problems and promoting realistic sustainability. The frameworks and extensive evidence provided by NIRN and the narrowing of implementation processes to key evidence based steps outlined by Myers, Durlack and Wandersman 2012 are two excellent resources for designing and managing implementations and for informing policy and practice.

\section{Parents and the Preschool PATHS Programme}

The issue of parental involvement arose spontaneously across preschool establishments Innovation, adaptation or ' drift' are often associated with loss of programme integrity and focus but they are also seen to be natural and inevitable occurrences as practitioners respond to the implementation needs arising across distinctive ecologies (Bumbarger and Perkins ,2008). Current innovations were interesting in the context of current UK policy to foster collaboration and integration of children's' services and support child and family mental health and wellbeing. To reduce and prevent preschool behaviour problems, some preventative preschool social and emotional programmes and approaches to parent training are effective strategies if evidenced and implemented appropriately. Integrating parent training with training for school staff and other practitioners seems promising and reflects policy models but requires fuller elaboration of the processes involved. Little is in fact known about the mechanisms or potential of different models of parental integration or engagement. Further exploration of this area seems fundamental to linking the principles of effective child management across home, school and communities.

\section{Summary of implications for policy and practice}

- Preschool social, emotional and behavioural problems are areas of urgent concern because of their widespread negative effects on wellbeing and attainment and longer term negative impact on quality of life.

- High quality evidence on what works is limited but studies flag up integration of programmes across contexts and recipients, for example training parents and teachers in a linked programme as likely to be most effective.

- Implementation frameworks and evidence based steps exist to guide effective programme delivery but reports of high quality comprehensive implementation models in research and practice are rare. Without routine application of implementation frameworks, effectiveness and development remain out of reach, even for well evidenced programmes.

- Case studies of frameworks and evidence based implementations are essential and 
instructive, detailing how various key components can be tackled and how adaptations and innovations arise and impact on delivery and development.

- More research is needed on different types of programme integration and diversification. More information is required on engagement and involvement of parents in successful programmes in how this can is facilitated and measured.

References

Aarons, G.A. (2004) Mental health provider attitudes toward adoption of evidence based -practice: The Evidence Based Practice Attitude Scale (EPBAS), Mental Health Services Research 6, 61-74

Allen, G. (2011) Early Intervention: The Next Steps -An independent Report To Her Majesty`s Government, HM Government, London.

Bierman, K.L and Welsh and J.A. (1997) Social relationship deficits in E.J. Mash and L.G. Terdal (Eds), Assessment of Childhood Disorders $3^{\text {rd }}$ Edit, pp. 328-365, NY Guilford Press

Blasé, K.A. , Van Dyke, M., Fixsen, D. and Wallace Bailley, F. (2012) Implementation Science: Key Concepts, Theory and Evidence for Practitioners in Educational Psychology in Kelly, B. and Perkins D.F. (2012), (Eds) Handbook of Implementation Science for Psychology in Education Cambridge University Press New York

Bumbarger, B.K. and Perkins, D. F. (2008) After randomised trials: issues related to the dissemination of evidence-based interventions. Journal of Children`s Services, Vol 3 (2), 55-64

Bywater T, Hutchings J, Linck P, Whitaker C.J., Daley D, Yeo S.T. and Edwards R.T. (2010), Incredible Years Parent Training Support for Foster Carers in Wales: A Multi-Centre Feasibility Study. Child Care Health and Development. doi:10.1111/j.1365-2214.2010.01155.x

Domitrovich, C. , Cortes, R.C. and Greenberg, M.T. (2007) Improving Young Children`s Social and Emotional Competence; A Randomized trial of the Preschool PATHS Curriculum Journal of Primary Prevention, Vol 28, No 2, 67-91. 
Domitrovich, C., Bradshaw, C.P., Greenberg, M.T., Embry, D., Poduska, J. and Nicholas, I. (2010) Integrated models of school based prevention: Logic and theory. Psychology in the Schools, Vol 47 (1), 71-88

Fantuzzo, J.W., Bulotsky, R., Fusco, R.A. and McWayne, C. (2005) An investigation of preschool classroom behavioral adjustment problems and social emotional school readiness competencies, Early Childhood Research Quarterly, 20, 259-275

Farrington, D.P. and Welsh, B.C. (2007), Saving Children form a Life of Crime: Early Risk Factors and Effective interventions. Oxford University Press, Oxford

Fixsen, D., Blasé, K.A., Wallace. (2009)Core Implementation Components, Research on Social Work Practice vol 19, no 5, 531-540

Flay, B.R., Biglan, A., Boruch, R. F., Castro, F.G., Gottfredson, D. and Kellam, S. (2005) Standards of Evidence: Criteria for efficacy, effectiveness and dissemination. Prevention Science, 6, 151-175.

Fox, L. Dunlap, G. Hemmeter, M.L.., Joseph, G.E. and Strain, P.S. (2003) The Teaching Pyramid: A model for supporting social competence and preventing challenging behaviour in young children. Young Child, 58, 4 48-52

Guide to `Getting it Right for Every Child` (GIRFEC), Scottish Government, 2014

Gorard, S and Huat See, B. (2013) Do Parental Involvement Interventions Increase Attainment? Review of the Evidence. Nuffield Foundation, University of Durham.

Guerra, N., Bradshaw CP., (2008) Linking the prevention of problem behaviors and positive youth development: Core competencies for positive youth development. New Directions in Child and Adolescent Development; 122, 1-17.

Huaing, T. and Kaiser, T. (2003) Behaviour problems of preschool children from low income families: Review of the literature. Topics in Early Childhood Special Education, Vol 23, no 4, 188-216

Hutchins, J and Gardner (2012) Support from the Start: Effective programmes for three to eight year olds. Journal of Children's Services, Vol 7 no 1, 29-40

Izard, C.E., Trentacosta, C.J., King, K.A and Mostow, A.J. (2004), An emotion based prevention program for Head Start children. Early Education and Development 15, 407, 422 
Kelly, B. and Perkins D.F. (2012) (Eds) Handbook of Implementation Science for Psychology in Education Cambridge University Press New York

Kelly, J.G., Ryan, A.M. and Altman, B.E. (2000), Understanding and changing social systems: An ecological view. In Rappaport, J. and Seidman, E. (Eds) Handbook of Community Psychology (pp 133159) Dordrecht, The Netherlands: Kluwer Academic Publishers

Mihalic, S. (2004) The Importance of Implementation Fidelity, Emotional and Behavioral Disorders in Youth, vol 4, no 4, 83-88

Myers, D.C. Durlack, J.A. and Wandersman, A., (2012), The Quality Implementation Framework: A Synthesis of Critical Steps in the Implementation Process American Journal of Community Psychology Dec; 50(3-4): 463-480

National Institute for Children`s Health and Social Care (Nice) 2006, London. Parent Training /Education Programmes in the Management of Children with Conduct Disorders,

Neill, D. (2013), Parents ' Views of the PATHS (Promoting Alternative Thinking Strategies) Curriculum. Unpublished thesis, part completion of MSc, Educational Psychology, University of Dundee

Patterson, G.R., Reid, J.B. and Dishion, T.J., (1992), A Social Interactional Approach, Vol 4, Anti- social Boys. Eugene, OR: Castalia

Rathvon, N. (2008) Effective School Interventions: Evidence Based Strategies for Improving Student Outcomes, Guilford Press, NY

Smith, B.J. and Fox, L. (2003) Systems of Service Delivery: A synthesis of evidence relevant to young children at risk or who have challenging behaviour .Tampa, FL. University of South Florida Centre for Evidence Based Practice: Young Children with Challenging Behavior.

Spoth, R., \& Greenberg, M. (2011) Impact challenges in community science-with-practice: Lessons from PROSPER on transformative practitioner-scientist partnerships and prevention infrastructure development. American Journal of Community Psychology, 48(1-2), 106-119.

Van Dyke, M., National Implementation Research Network, Presentation: Implementation Science, CELCIS (Centre for Excellence for Looked after Children in Scotland), University of Strathclyde, October $21^{\text {st }} 2014$. 
1

2

3

4

5

6

7

8

9

10

11

12

13

14

15

16

17

18

19

20

21

22

23

24

25

26

27

28

29

30

31

32

33

34

35

36

37

38

39

40

41

42

43

44

45

46

47

48

49

50

51

52

53

54

55

56

57

58

59

60 